\title{
TEKNIK MEMBUAT NILAI SEMESTER MENGGUNAKAN MICROSOFT EXCEL
}

\author{
Ibnu Ziad ${ }^{1}$ \\ Jurusan Teknik Elektro, Politeknik Negeri Sriwijaya, \\ email : ibnupoltek1@gmail.com \\ Rita Martini \\ Jurusan Akuntansi, Politeknik Negeri Sriwijaya \\ email : martinirita65@gmail.com \\ Gst. Ayu Oka Windarti ${ }^{3}$ \\ Jurusan Administrasi Bisnis, Politeknik Negeri Sriwijaya \\ email : ayuoka1960@gmail.com
}

\begin{abstract}
Making semester scores using the Microsoft Excel program aims to help lecturers or teachers in making semester grades for students, and the results are more rigorous than manually made. Our goal in conducting this research is to provide knowledge to the lecturers or teachers, and also to know where to use this Microsoft Excel program. The method or approach to the lecturers and teachers is to hold information to them. And from the results of our research or counseling, it turned out that they were very enthusiastic, and they have not known that the Microsoft Excel program can be used to make semester grades for students.
\end{abstract}

Keyword: microsoft Ecxel, program, enthusiastic, lecturer, teacher

\section{PENDAHULUAN}

Program pengabdian ini bertujuan untuk: 1) Memberikan pengetahuan dan pemahaman kepada Dosen-dosen atau Guru-guru mengenai cara-cara yang dapat mereka lakukan untuk menggunakan program Microsoft Excel untuk membuat Nilai Semester mahasiswa atau siswa, dan 2) Untuk meningkatkan kesadaran Dosendosen atau Guru-guru akan pentingnya penggunaan program Microsoft Excel untuk membuat Nilai Semester mahasiswa atau siswa. Penyuluhan penggunaan software Microsoft Excel ini akan membantu Dosen-dosen atau Guru-guru sehingga akan memberikan hasil yang nyata berupa peningkatan kinerja pegawai sehingga kualitas lulusan yang dihasilkan akan lebih baik cepat, dan berkualitas di masa-masa yang akan datang. Kondisi seperti ini dapat juga membantu pihak pimpinan selaku pengelola pekerjaan-pekerjaan yang dikerjakan oleh Dosen-dosen dan Guru-guru.

Dengan bertambahnya pengetahuan Dosendosen dan Guru-gurun dalam bidang program Microsoft Excel berarti juga memberikan kesempatan kepada Dosen-dosen dan Guru-guru sehingga tidak perlu harus membuat Nilai Semester secara manual, karena kekurang pahaman mereka dengan program komputer software Microsoft Excel. Program Microsoft Excel yang perlu dipelajari diantaranya adalah pembuatan Nilai Ujian Tengah Semester, Nilai Ujian Akhir Semester, Nilai dalam bentuk angka, dan Nilai dalam bentuk huruf, dan Nilai apabila perlu kami berikan juga Nilai Kelakuan Mahasiswa dan Siswa. Bagi Dosen-dosen dan Guru-guru ini adalah merubah Nilai Semester dari yang dibuat manual menjadi Nilai Semester yang dibuat dengan bantuan komputer menggunakan program Microsoft Excel.

Setelah tabel dibuat, disini kita ambil nilai tahun akademik 2013/2014, dan tabel ini berisikan nilai semester mahasiswa, karena perubahan yang akan dibuat mulai dari semester awal, kemudian untuk tahap selanjutnya akan kita rubah juga untuk semester selanjutnya. Ketidakseimbangan pengetahuan Dosen-dosen dan Guru-guru dalam menguasai program Microsoft Excel dalam membuat Nilai Semester akan memperlambat perkerjaan mereka sehingga waktu yang dipergunakan untuk itu bisa dipakai untuk masalah lain. Pengetahuan Dosen-dosen dan Guru-guru ini dalam memahami program Microsoft Excel dalam membuat nilai semester, dapat membagikan ilmunya ini kepada Dosen-dosen dan Guru-guru yang lain dalam kota Palembang. 
Pemakaian program komputer Software Microsoft Excel ini tidak terlalu sulit hanya saja harus mempunyai komputer dan printer agar hasil dari Microsoft Exel bisa di cetak di kertas dan dijadikan sebagai bukti penilaian yang diberikan dosen dan guru. Untuk memberikan pemahaman dan meningkatkan pengetahuan dan Guru-guru ini maka kami mencoba memberikan pengetahuan yang kami punyai yang akan diberikan kepada Dosen-dosendan Guru-guru ini yang nantinya akan diterapkan untuk pembuatan Nilai Semester. Apabila dikaitkan dengan kegiatan pengabdian kepada masyarakat maka kegiatan penyuluhan ini dapat saja dilakukan secara berkesinambungan.

Tabel 1. Contoh Penilaian Nilai Semester

\begin{tabular}{|l|c|r|r|r|r|c|}
\hline Nama & UTS1 & UTS2 & UAS & Rata-rata & Angka & Kelakuan \\
\hline Aidil Furkon & 65 & 70 & 70 & 68.75 & B & 3 \\
\hline Amrina Rosyada & 70 & 75 & 65 & 68.75 & B & 3 \\
\hline Diko Meirodiansyah & 60 & 70 & 75 & 70 & B & 3 \\
\hline Dwi Oktanindy & 70 & 75 & 65 & 68.75 & B & 3 \\
\hline Eka Putri Damayanti & 65 & 60 & 75 & 68.75 & B & 3 \\
\hline Hardiyanti & 60 & 65 & 60 & 61.25 & C & 2 \\
\hline Intan Angraini & 75 & 70 & 60 & 66.25 & B & 3 \\
\hline Ivone Sisilia & 80 & 85 & 90 & 86.25 & A & 3 \\
\hline Kgs Ahmad Fauzan & 65 & 60 & 75 & 68.75 & B & 3 \\
\hline M. Rizky Permana Putra & 38 & 30 & 40 & 37 & E & 1 \\
\hline Muhamat Putra Maiwa & 54 & 53 & 53 & 53.25 & D & 1 \\
\hline Muhammad Apriyansyah Putra & 75 & 75 & 75 & 75 & B & 3 \\
\hline Octaviani Aulia & 70 & 70 & 70 & 70 & B & 3 \\
\hline Rahayu Murni Syafitri & 50 & 52 & 50 & 50.5 & D & 1 \\
\hline Roslina & 65 & 65 & 70 & 67.5 & B & 3 \\
\hline Septi Dwi Permatasari & 70 & 70 & 75 & 72.5 & B & 3 \\
\hline
\end{tabular}

Rumus untuk membuat nilai rata-rata adalah

Rata-rata $=+\operatorname{SUM}(((\mathrm{B} 3+\mathrm{C} 3) / 2)+(\mathrm{D} 3)) / 2$

Rumus untuk membuat angka adalah

Angka = IF(E4> 79.9,"A",IF(E4>65.9,"B",IF(E4>53.9,"C",IF(E4>39.9,"D","E"))))

Rumus untuk membuat kelakuan adalah

Kelakuan = IF(E4> 79.9,"3",IF(E4>65.9,"3",IF(E4>53.9,"2",IF(E4>39.9,"1","1"))))

\section{IDENTIFIKASI MASALAH}


Dengan memberikan ceramah dan pengarahan yang dipandu dengan peragaan bagaimana cara penggunaan program Microsoft Excel yang benar, cara pengoperasian yang tepat dan praktis. Sesekali diadakan diskusi terhadap bagian-bagian tertentu dari problema bagaimana menggunakan software Microsoft Excel dalam presentasi ini serta di usahakan software Microsoft Excel ini dipakai dalam metode pembuatan nilai semester untuk Dosen-dosen dan Guru-guru ini. Evaluasi dapat ditinjau dari hasil diskusi yang memperhatikan sejauh mana daya serap Dosen-dosen dan Guru-guru terhadap kegiatan yang telah dilaksanakan. Atau dengan meminta mereka memperagakan prosedur yang telah diberikan.

\section{METODELOGI PELAKSANAAN}

Kegiatan yang dilakukan dalam penyuluhan ini adalah penggunaan program Microsoft Excel untuk pembuatan nilai semester mahasiswa dan siswa Jurusan oleh Dosen-dosen dan Guru-guru.

Peralatan-peralatan yang biasa dipakai Laptop, Infocus, Layar untuk tampilan atau bisa juga memakai Smart Board apabila kita menginginkan tulisan yang kita tulis di Smart Board tersebut mau kita simpan di Laptop.

Dengan mempelajari program Microsoft Excel ini diharapkan kualitas Dosen-dosen dan Guru ini akan semakin meningkat sehubungan dengan perkembangan teknologi yang semakin lama semakin meningkat terutama di dalam menggunakan program Microsoft Excel ini.

\section{HASIL DAN PEMBAHASAN}

Kegiatan penyuluhan yang dilakukan mendapat respon positif dari Dosen-dosen dan Guru-guru. Pengetahuan praktis yang mereka butuhkan dalam upaya pemakaian program Microsoft Excel dalam kegiatan mepresentasikan pembuatan nilai semester dirasakan masih kurang, terlebih lagi mereka belum memiliki pengetahuan mengenai penggunaan software Microsoft Excel untuk membuat nilai semester mahasiswa, Dalam penyuluhan yang telah dilakukan diberikan petunjuk secara praktis mengenai cara-cara yang dapat dilakukan secara sendiri oleh Dosen-dosen dan Guru-guru untuk menggunakan software Microsoft Excel dengan baik dan benar.
Kegiatan semacam ini dirasa perlu untuk dilaksanakan secara berkelanjutan karena pengetahuan yang diterima sangat bermanfaat bagi Dosen-dosen dan Guru-guru.

Menurut tim penyuluh, dengan peragaan yang mempraktekkan cara pemakaian program Microsoft Excel ini memberikan kemudahan bagi mereka untuk lebih cepat menanggapi. Namun kesulitan yang dialami adalah masalah tempat dan waktu untuk mengumpulkan Dosendosen dan Guru- guru ini dalam waktu yang bersamaan. Jalan keluarnya adalah dengan menambah waktu penyuluhan secara berperiode dan berkelanjutan.

\subsection{LOKASI PENYULUHAN}

Penyuluhan ini pertama di Fakultas Teknik Universitas Palembang. Ada 2 Jurusan di Fakultas Teknik Universitas Palembang ini yaitu Jurusan Teknik Sipil dan Jurusan Teknik Elektro, dan penyuluhan ini hanya kami lakukan di Jurusan Teknik Elektro. Jumlah Dosendosen Tetap Jurusan Teknik Elektro Universitas Palembang berjumlah 12 orang dan dosen Luar Biasa sekitar 11 orang yang terdiri 1 orang Ketua Jurusan, 1 orang Sekretaris Jurusan, 1 orang Kepala Laboratorium Teknik Elektro serta dibantu oleh 2 orang tenaga Administrasi. Ada juga Dosen Teknik Elektro ini menjabat sebagai Pembantu Dekan III Fakultas Teknik, tetapi kebanyakan yang menjabat Pembantu Dekan ini dari Jurusan Teknik Sipil Universitas Palembang.

Ke dua dilakukan di SD Negeri 8, dan data-data dari SD ini telah kami minta yaitu jumlah guru SD Negeri 8 termasuk Kepala Sekolah beserta Wakil berjumlah 21 orang guru Pegawai Negeri Sipil, 4 orang guru honor, 1 orang Tata Usaha honor, 1 orang penjaga sekolah PNS, 1 orang penjaga sekolah honor dan jumlah keseluruhan murid SD Negeri 8 ini adalah 658 orang, serta SD Negeri 8 ini termasuk SD Teladan

\subsection{DIAGRAM ALIR ORGANISASI}

Diagram alir dari Universitas Palembang dan SD Negeri 8 ini bisa dilihat di bawah ini. 


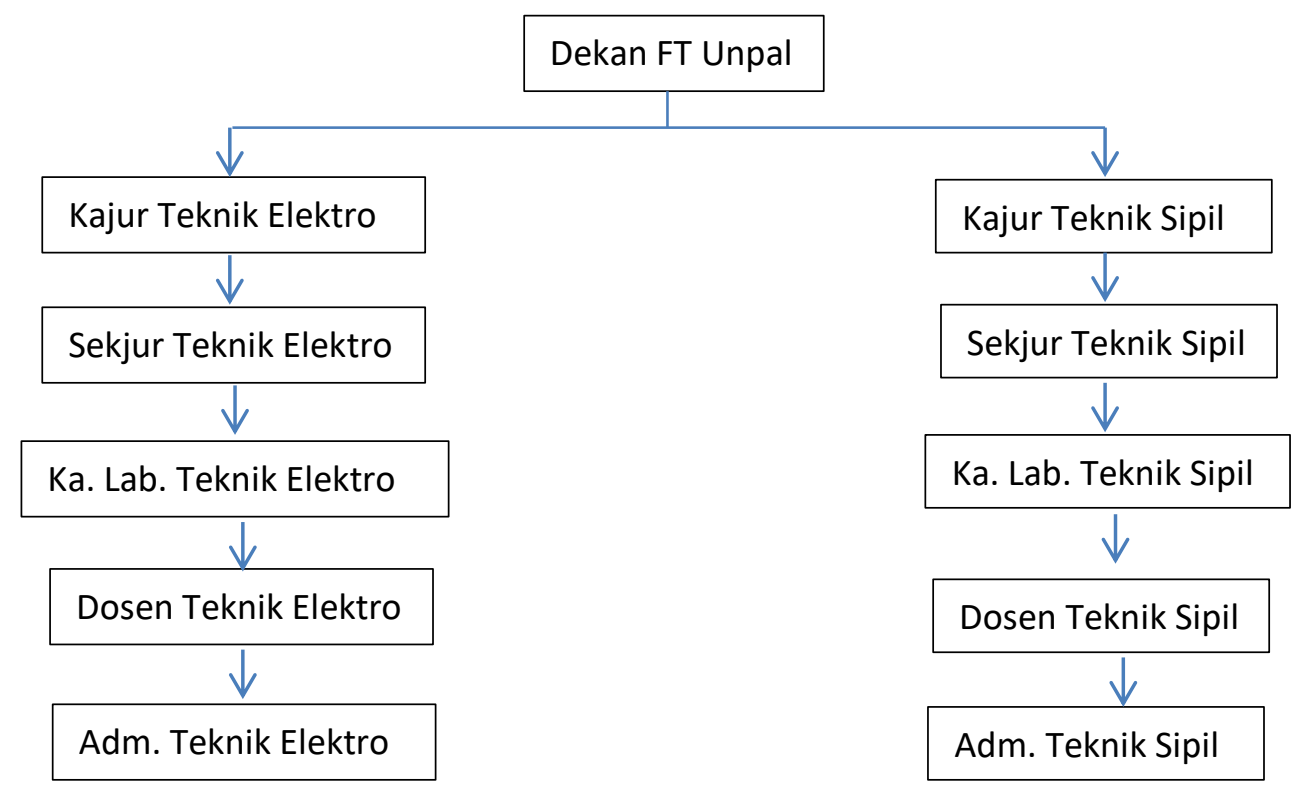

Gambar 1. Struktur Organisasi Fakultas Teknik Universitas Palembang

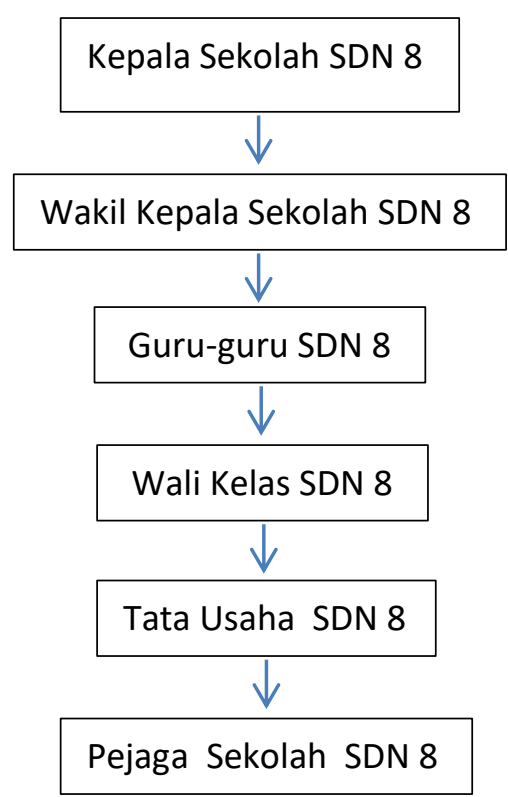

Gambar 2. Struktur Organisasi Sekolah Dasar Negeri 8

\subsection{TEST KEMAMPUAN}

Untuk mengetahui

keberhasilan penyuluhan ini, maka kami rancangan evaluasi untuk dosen FT Unpal dan guru-guru SDN 8.

Evaluasi dilakukan kepada para peserta setelah penyampaian materi pelatihan dengan mempraktekkan langsung kepada Dosen-dosen Jurusan Teknik Elektro Universitas Palembang yaitu dengan tanya jawab terhadap materi yang diberikan. Parameter yang akan dievaluasi seperti tertera pada tabel 2. 
Tabel 2. Rancangan Evaluasi

\begin{tabular}{|l|l|l|l|l|}
\hline \multirow{2}{*}{ No } & \multirow{2}{*}{ PARAMETER } & \multicolumn{3}{|l|}{ PRESENTASE (\%) } \\
\cline { 3 - 5 } & Penerimaan Materi & & & \\
\hline 1 & Pemahaman & & & \\
\hline 3 & Aplikasi & & & \\
\hline
\end{tabular}

$$
\begin{aligned}
& \text { Keterangan: } \\
& \text { A = Sangat Baik } \quad B=\text { Baik } \quad C=\text { Cukup }
\end{aligned}
$$

Diharapkan materi penyuluhan ini dapat diterima dengan baik (minimal 70\% seluruh materi dikuasai oleh para peserta penyuluhan). Dari hasil evaluasi kami, maka didapatkan dari dosen-dosen FT Unpal dan guru-guru SDN 8 rata-rata mendapat nilai 80 , berarti penyuluhan ini berhasil.

\section{KESIMPULAN}

Pengetahuan praktis tentang cara pemakaian program Microsoft Excel ini dalam nilai semester secara tepat dan benar dapat diterima oleh Dosen-dosen dan Guruguru yang diberi penyuluhan. Dengan demikian dapat diartikan bahwa melalui kegiatan penyuluhan dapat disampaikan halhal yang bermanfaat untuk menumbuhkan kesadaran warga masyarakat akan pentingnya pengetahuan yang bersifat terapan dan terpakai oleh mereka seharihari.

Materi yang disampaikan dirasakan cukup membantu Dosen-dosen dan Guruguru ini untuk memahami cara pemakaian program Microsoft Excel ini secara mandiri. Dengan mengetahui cara pemakaian program Microsoft Excel ini berarti dapat membantu kelanacaran tugas Dosen-dosen dan Guru-guru itu sendiri.

\section{UCAPAN TERIMA KASIH}

Kami mengucapkan banyak terima kasih kepada:

- Bapak Dr. Ing, Ahmad Taqwa, M.T., selaku

Direktur Politeknik Negeri Sriwijaya.
- Bapak Carlos, R.S., S.T., M.T., selaku Pembantu Direktur I Politeknik Negeri Sriwijaya.

- Bapak Ir. Jaksen M. Amin, M.Si., selaku Kepala Pusat Penelitian dan Pengabdian Kepada Masyarakat Politeknik Negeri Sriwijaya.

- Ibu Dr, Rita Martini, S.E., M.Si., selaku Sekretaris Kepala Pusat Penelitian dan Pengabdian Kepada Masyarakat Politeknik Negeri Sriwijaya.

- Bapak Yudi Wijanarko, S.T., M.T., selaku Ketua Jurusan Teknik Elektro Politeknik Negeri Sriwijaya.

- Bapak Ir. S.S. Purwanto, M.T., selaku Dekan Fakultas Teknik Universitas Palembang.

- Ibu Yuliarni, S.Pd., selaku Kepala Sekolah SD Negeri 8 Palembang.

\section{REFERENSI}

Joe Kraynak. 2003. Absolute Beginner's Guide to Microsoft Office Excel 2003. Jakarta: Penerbit Gramedia.

Kenny CH. Titjo. 2016. Pengertian Tes, Pengukuran, Evaluasi, dan Asesmen. Jakarta.

kennytitjo.blogspot.co.id

Madcoms Madiun. 2013. Kupas Tuntas Microsoft Excel 2013. Yokyakarta. Penerbit CV Andi Offset

Nancy D. Lewis. 2003. Easy Microsoft Office Excel 2003. Jakarta: Penerbit Erlangga 